\title{
Influence of some physical factors on the growth and sporulation of entomopathogenic fungi
}

\author{
JERZY PIATTKOWSKI and ANETA KRZYŻEWSKA
}

Institute of Genetics and Microbiology, University of Wrocław

Przybyszewskiego 63/77, PL-51-148 Wrocław, jurekp@microb.uni.wroc.pl

Piątkowski J., Krzyżewska A.: Influence of some physical factors on the growth and sporulation of entomopathogenic fungi. Acta Mycol. 42 (2):255-265, 2007.

The objective of the study was to examine, how some physical factors and inoculation techniques affect the growth and sporulation of three insecticidal fungal strains, Hirsutella tompsonii, Paecilomyces sp., and Pandora sp. Although the methods of inoculation, as well as such physical parameters as temperature, the osmotic value of the habitat and UV radiation, exerted an influence on the above-mentioned features of the fungi, their contribution varied from one strain to another. Some of the effects, however (e.g., the production of filamentous structures by Pandora, or the lethal action of glycerol on Pandora), require a close examination.

Key words: entomopathogenic fungi, phisical factors, sporulation, growth of fungi

\section{INTRODUCTION}

Apart from unquestionable advantages, the application of insecticidal chemicals has a number of major drawbacks. These substances are toxic not only to the target insects but to the beneficial ones as well. They are also known for their harmful effect on human health. During long-term exposure, the target insects develop resistant forms to the insecticide applied. In the process of biotransformation by bacteria, a variety of new compounds may be produced, including cancerogens (Różański 1992).

For these reasons, many investigators have directed their attention to the use of a natural enemy of a pest as a less harmful environmental pollutant. Of those investigations, the one into the entomopathogenic fungi as manipulative tools in biological control deserves special consideration. In general, the fungi are able to grow under laboratory conditions (Pate rs on et al. 1987) but the production of efficient and inexpensive commercial preparations require mastering the competence for an effective and low-cost cultivation of the fungi, as well as for making them produce a great amount of spores. The efforts of the scientists have also focused on the secondary 
metabolites released by the fungi, which certainly play an important role in the process of infection and killing pests.

All that mean, that the production of efficient preparations on the entomopathogenic fungi basis requires information about the biology of the organisms, their nutritional needs and their response to physical factors. Spore formation, germination, hyphal and spore survival are influenced by temperature, humidity, light, organic pollutants, salinity, antagonists, etc. (Carruthers, Hural 1990).

Investigations performed so far have revealed that the response of the fungi to the habitat factors depends on the species and ecotype involved and that the activity of the fungi against their host follows a seasonal pattern. Thus, Beauveria bassiana infects Leptinotarsa decemlineata more often in the summer and Paecilomyces farinosus in the autumn and winter seasons (Bajan, Kmitova 1997). With Entomophthora destruens and Conidiobolus thromboides, the extent of spore production depends on the season of the year, or (to be more exact) probably on the length of daylight (Krejzova 1988).

An important factor, both inhibiting and stimulating the growth of the organisms, is temperature, which seems to affect directly the ability to infect (Miętkiewski et al. 1994). It is a well established fact that the optimal temperature for the species of the genus Entomophthora (e.g., E. ignobilis, E. obscura, E. exitialis, or E. virulen$t a)$, which provides their most dynamic growth, ranges between 24 and $27^{\circ} \mathrm{C}(\mathrm{Hall}$, Bell 1961). A similarly stimulating effect of this temperature range on the growth of mycelium has been reported for the genera Beauveria, Metarrizium, and Paecilomyces (Halsworth, Magan 1999). Further study has revealed that the optimal temperatures for hyphal survival are identical with those for the survival of spores (Brobyn et al. 1985).

The temperature factor affects the duration of sporulation; e.g., in Erynia neoaphidis the temperature of $5^{\circ} \mathrm{C}$ inhibits sporulation completely (Drompf et al.1998). The spores of Entomophthora apiculata, E. virulenta and E. coronata are deactivated by extreme temperatures $-8^{\circ} \mathrm{C}$ and $+36^{\circ} \mathrm{C}$ (Yendol 1968).

It has been reported that hit shock proteins appear in entomopathogenic fungi and that their appearance is induced by the habitat of $45^{\circ} \mathrm{C}$ (Xavier, Khachatourians, 1996).

Humidity exerts a direct influence on fungi, both on vegetative cells and spores. The optimal relative humidity oscillates within a wide range, depending on the species involved. For example, Entomophthora aphidis and E. thaxteriana discharge spores only when humidity ranges between 70 and $90 \%$. Under such conditions, the spores survive a few days, but in cooler air - several weeks or even months (Wild ing 1973). In the majority of the genera, germination is inhibited even at $90 \%$ or lower humidity, but in some Entomophthora conidium may germinate and infect insects at humidity lower than 50\% (Uziel, Kennet 1991). In many fungi, the 24-hour rhythm of spore production is daylight-dependent.

Light accounts for a variety of effects. It has been found that the extent of sporulation in Entomophthora virulenta is significantly higher in darkness than in light under laboratory conditions (La tg e et al. 1978), in contrast to Entomophthora spheroderma which discharges more conidium during daylight, both in vivo and in vitro. Light-dependent periodicity of spore release has also been reported for Erynia radi- 
cans. This periodicity appeared after exposure of a culture alternately to light and dark (Yam amoto, Aoki 1983).

There are not very many references to the influence of physical factors on entomopathogenic fungi in the available literature, although fungi are known to be strongly affected by this kind of factors. So far, the reports on these fungi have focused on the optimal growth medium for cultivation and on the basic biological properties, especially those involved in such physiological activities as sporulation, production of secondary metabolites and infection of the host insect.

The objective of the experimental study reported on in the present paper was to throw new light on the variety of physical and environmental factors which affect the entomopathogenic strains belonging to different genera. For the purpose of our study, the genera Paecilomyces, Pandora and Hirsutella were chosen.

The fungi under study differ in the morphology of their mycelium, in resistance to some unfavourable external factors and in the mode of sporulation. The chosen fungi represent different unrelated genera, thus enabling the verification of whether the observed effects produced by the physical factors being tested are common to all fungi or depend on the composition and physiological properties of a particular fungal organism.

\section{MATERIALS AND METHODS}

Strains used in the investigations: Pandora sp. isolated from the aphids Protrama ranunculi; Paecilomyces sp. from a larva of the family Cantharidae, and Hirsutella thompsonii Fischer from Phylocoptura oleivora. All the strains were obtained by courtesy of Prof. Bałazy, Research Centre for Agricultural and Forest Environment, Polish Academy of Sciences, Poznan.

Measurement of the rate of mycelium growth: Round discs of mycelium ( $4 \mathrm{~mm}$ in diameter) were cut out from the 7-day preculture on the solid YPG medium (Yeast Extract 1\%, Bacto Pepton 1\%, glucose 2\%, Bacto Agar 2\%). Each disc was placed at the central point of the medium in a Petri dish and incubated at $22^{\circ} \mathrm{C}$. Mycelium growth was measured every 24 hours.

Relation between mycelium growth and inoculation method. The mycelium discs were translocated into a tube with $0.5 \mathrm{ml}$ saline $(0.9 \% \mathrm{NaCl})$, and afterwards ground against the wall of the tube to obtain sols of fragmented mycelium. The solution prepared in this way was dropped onto the central part of the solid YPG medium, spread over the whole medium surface, or streaked with a reductive streack using a loop. The mycelium discs were also placed on the solid medium without previous grinding. In order to observe the growth of the mycelium inside the solid medium, the discs were flooded (after being placed on the solid medium) with the same, still warm enough $\left(50^{\circ} \mathrm{C}\right)$ liquid medium.

Effect of low temperature: The experiments were performed with the following media: saline $(0.9 \% \mathrm{NaCl})-\operatorname{medium} A$; fluid medium for the storage of bacterial strains consisting of $1 \%$ Trypton, $1 \%$ Yeast Extract and $0.5 \% \mathrm{NaCl}, 1000 \mathrm{ml}$ of this medium were treated with $450 \mathrm{ml}$ of $50 \%$ glycerol - medium $B$; medium for the storage of yeast cells consisting of Yeast Extract,10g, Bacto Pepton, 10g, Glucose, 20g, Glycerol, $250 \mathrm{ml}$ and distilled water, $750 \mathrm{ml}-$ medium C. $0.5 \mathrm{ml}$ of the liquid media was poured into the Eppendorf tubes and thereafter $4 \mathrm{~mm}$ discs of fungal mycelium 
were added. All the media were kept in a dark room at $22^{\circ} \mathrm{C}$ and in a fridge at $4^{\circ} \mathrm{C}$ and minus $72^{\circ} \mathrm{C}$. After 24 hours, 7 days and 7 weeks of incubation, the discs were replaced on the solid YPG medium.

Effect of glycerol concentration: The mycelium discs were incubated in Eppendorf tubes with 60-, 30-, 15-, 7.5-, and 3.25\% of glycerol. Mycelium discs kept in saline for 24 hours acted as control. After 24-hour incubation at $22^{\circ} \mathrm{C}$, the discs were replaced on the solid YPG medium and observed for 10 days.

Effect of osmotic value: The same experiments were carried out using different $\mathrm{NaCl}$ concentrations: $0.006 \mathrm{M}$ (hypotonic solution), $0.06 \mathrm{M}$ (hypotonic solution), and $0.6 \mathrm{M}$ (hypertonic solution). Discs icubated in distillate water for 24 hours were used as control.

Effect of UV radiation: The mycelium discs were placed in the middle of the Petri dish. After 4 days of incubation at $22^{\circ} \mathrm{C}$, they were exposed to UV radiation $(\lambda=260$ $\mathrm{nm}$ ) for 1, 5, 10,30 and $60 \mathrm{~min}$. The control comprised non-irradiated discs.

\section{RESULTS}

As shown by the growth rate analysis of the three fungi species used in the investigations, the most dynamic growth on the solid medium was that of Pandora. The two other strains, Hirsutella and Paecilomyces, grew equally fast, but significantly slower than Pandora. After 11 days of incubation, Pandora attained a $90 \mathrm{~mm}$ diameter, almost equal to the diameter of the medium plate, so the growth process had to be discontinued (Fig. 1). At the initial stage, the rate of growth increased continually for approximately 6 days of incubation. After that time, on days 6 to 11, the rate of mycelium spreading was stable. Paecilomyces and Hirsutella achieved a $30 \mathrm{~mm}$ diameter after 25 days. On days 25 to 30 the rate of growth decreased, and from day 30 on, growth no longer continued.

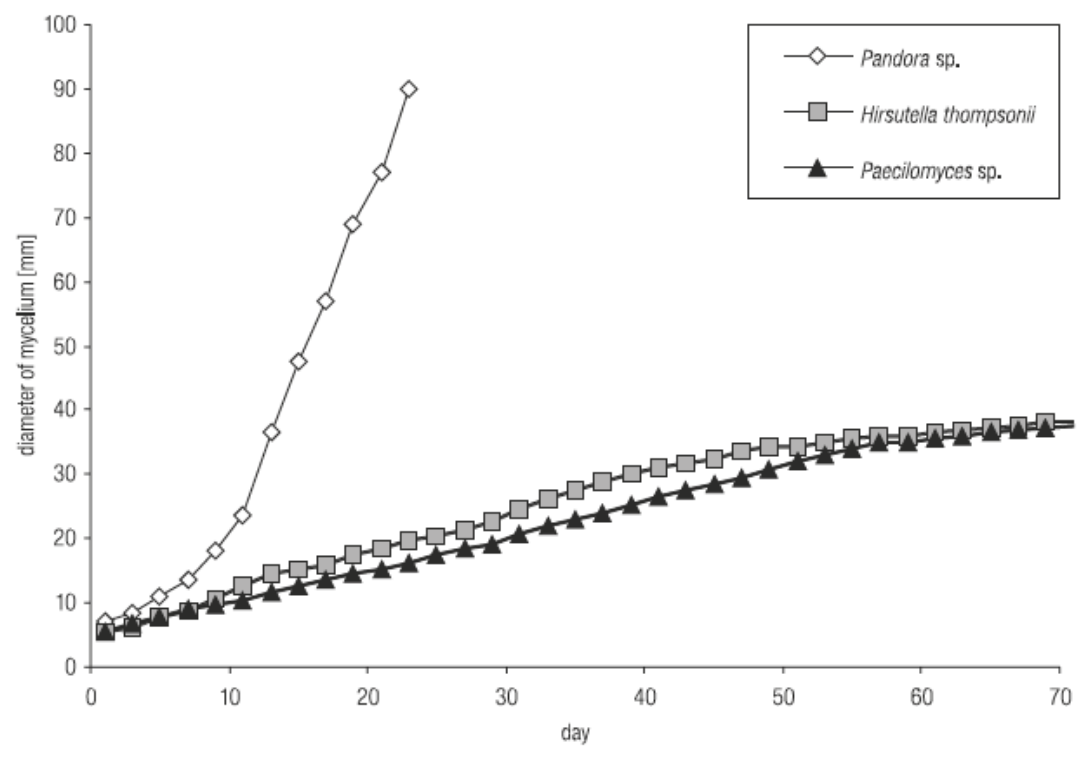

Fig. 1. Growth of entomopathogenic fungi on YPG full medium. 
The method of hyphal inoculation into the growth medium was also an important factor to which each of the three strains responded differently. Pandora was growing in the form of a colony, when the suspension of the previously ground mycelium was dropped at the centre of the solid medium or spread over the whole surface of the medium by means of a spreader. Pandora placed on the plate surface with a reductive streak using a loop showed a poorer growth when the cells were taken from the surface of the fungus or from the suspension of ground mycelium in saline. There was no growth at all when the Pandora cells were flooded with the medium, which implies that with Pandora deep inoculation is without any meaning. On the other hand, Hirsutella and Paecilomyces were growing quite well regardless of the inoculation method applied. Only the Paecilomyces sp. strain changed the morphology of its colony when plated deeply. The colony was plain but the pink colour typically occuring on the mycelium was no longer produced.

In order to verify the viability of the fungi at low temperature, a saline $(0.9 \%$ $\mathrm{NaCl}$ ) and a glycerol medium was used for the storage of the microorganisms at +6 , $-18,-72^{\circ} \mathrm{C}$, the temperature for the control being $22^{\circ} \mathrm{C}$ (Tabs 1,2 and 3 ).

As shown by these data, Pandora sp. exhibited a very high sensitivity to the negative temperatures used. This strain was able to survive 7 weeks when kept in saline

Table 1

Growth and sporulation of Pandora sp. related to time of exposure to various temperatures for different media

\begin{tabular}{|c|c|c|c|c|c|}
\hline Time & $22^{\circ} \mathrm{C}$ & $6^{\circ} \mathrm{C}$ & $-18^{\circ} \mathrm{C}$ & $-72^{\circ} \mathrm{C}$ & Medium \\
\hline 24 hours & ++ & +++ spores & - & + & $\mathrm{A}$ \\
\hline 7 days & ++ & +++ & - & + & $\mathrm{A}$ \\
\hline 7 weeks & - & - & - & - & $\mathrm{A}$ \\
\hline 24 hours & +++ spores & +++ spores & + & - & $\mathrm{B}$ \\
\hline 7 days & +++ spores & +++ spores & - & - & $\mathrm{B}$ \\
\hline 7 weeks & - & - & - & - & $\mathrm{B}$ \\
\hline 24 hours & + & +++ & - & - & $\mathrm{C}$ \\
\hline 7 days & - & - & - & - & $\mathrm{C}$ \\
\hline 7 weeks & - & - & - & - & $\mathrm{C}$ \\
\hline
\end{tabular}

Table 2

Growth and sporulation of Paecilomyces sp. related to time of exposure to various temperatures for different media

\begin{tabular}{|c|c|c|c|c|c|}
\hline Time & $22^{\circ} \mathrm{C}$ & $6^{\circ} \mathrm{C}$ & $-18^{\circ} \mathrm{C}$ & $-72^{\circ} \mathrm{C}$ & Medium \\
\hline 24 hours & ++ & +++ coremia & +++ & +++ coremia & $\mathrm{A}$ \\
\hline 7 days & ++ & ++ & ++ & +++ coremia & $\mathrm{A}$ \\
\hline 7 weeks & + & +++ & ++ coremia & +++ coremia & $\mathrm{A}$ \\
\hline 24 hours & +++ & +++ & +++ & +++ coremia & $\mathrm{B}$ \\
\hline 7 days & +++ & + & +++ coremia & +++ coremia & $\mathrm{B}$ \\
\hline 7 weeks & ++ & + & ++ & +++ & $\mathrm{B}$ \\
\hline 24 hours & +++ & +++ & +++ coremia & +++ & $\mathrm{C}$ \\
\hline 7 days & - & +++ & +++ & +++ & $\mathrm{C}$ \\
\hline 7 weeks & + & ++ & ++ & +++ & \\
\hline
\end{tabular}


Table 3

Growth and sporulation of Hirsutella tompsonii related to time of exposure to various temperatures for different media

\begin{tabular}{|c|c|c|c|c|c|}
\hline Time & $22^{\circ} \mathrm{C}$ & $6{ }^{\circ} \mathrm{C}$ & $-18^{\circ} \mathrm{C}$ & $-72^{\circ} \mathrm{C}$ & Medium \\
\hline 24 hours & +++ & +++ & +++ & +++ & $\mathrm{A}$ \\
\hline 7 days & +++ & +++ & +++ & +++ & $\mathrm{A}$ \\
\hline 7 weeks & ++ & ++ & ++ & ++ & $\mathrm{A}$ \\
\hline 24 hours & +++ & +++ & +++ & +++ & $\mathrm{B}$ \\
\hline 7 days & +++ & +++ & +++ & +++ & $\mathrm{B}$ \\
\hline 7 weeks & ++ & ++ & ++ & ++ & $\mathrm{B}$ \\
\hline 24 hours & +++ & +++ & +++ & +++ & $\mathrm{C}$ \\
\hline 7 days & +++ & +++ & +++ & +++ & $\mathrm{C}$ \\
\hline 7 weeks & - & - & + & ++ & $\mathrm{C}$ \\
\hline
\end{tabular}

at room temperature, and only 7 days when stored in the glycerol medium. After 24 hours of incubation in saline at $6^{\circ} \mathrm{C}$, there was an induction of spore formation, but no sporulation occured when the time of incubation was extended to 7 days. It is interesting to note that in the glycerol medium sporulation becomes visible after 24 hours and 7 days of incubation.

The Paecilomyces sp. strain was found to be more resistant to the temperature used in the experiments, it survived within the temperature range of $6^{\circ} \mathrm{C}$ to minus $72^{\circ} \mathrm{C}$. A longer exposure to the deficiency of nutrients in the habitat had an adverse effect on the ability of the strain to reconstruct a colony. Furthermore, as it can be infered from Table 2, at some of the temperatures and incubation times applied, the induction of an asexual reproduction structure was observed in Paecilomyces. These structures (referred to as coremia) appeared after different time at minus $18^{\circ} \mathrm{C}$ and depended on the type of the medium used. Coremia also appeared at each incubation time in saline at minus $72^{\circ} \mathrm{C}$, as well as after 24 hours and 7 days of incubation in the glycerol medium at minus $72^{\circ} \mathrm{C}$. These structures did not form when the strain was kept at minus $72^{\circ} \mathrm{C}$ in the glycerol medium for yeast storage and when the temperature of incubation was $22^{\circ} \mathrm{C}$, as well as in any medium variant at $6^{\circ} \mathrm{C}$.

As for Hirsutella thompsonii, full growth occured after keeping this fungus in whatever variant of temperature, medium or time except 7 weeks in the glycerol medium for yeast. In this medium, Hirsutella survived 7 weeks, but only if temperature was drastically decreased. This finding is important to the storage of these strains.

The glycerol medium for the storage of bacterial and yeast strains is used with success at temperatures even as low as minus $70^{\circ} \mathrm{C}$. As expected, Paecilomyces and Hirsutella were able to endure such temperature even for 7 weeks. But as it can be infered from table 1, Pandora did not survive under these conditions, even though the habitat was less drastic: 24 hours of incubation and minus $18^{\circ} \mathrm{C}$.

In order to explain the unexpected behaviour of Pandora, we decided to examine the effect of different glycerol concentrations on the rate of survival. To eliminate the influence of the water crystals that form at low temperature and may account for the killing of the cells, use was made of room temperature $\left(22^{\circ} \mathrm{C}\right)$ alone.

The glycerol concentrations of choice were $30 ; 15 ; 7.5$; and $3.25 \%$. After incubation of the Pandora mycelium in these variants of glycerol solutions, the discs were 


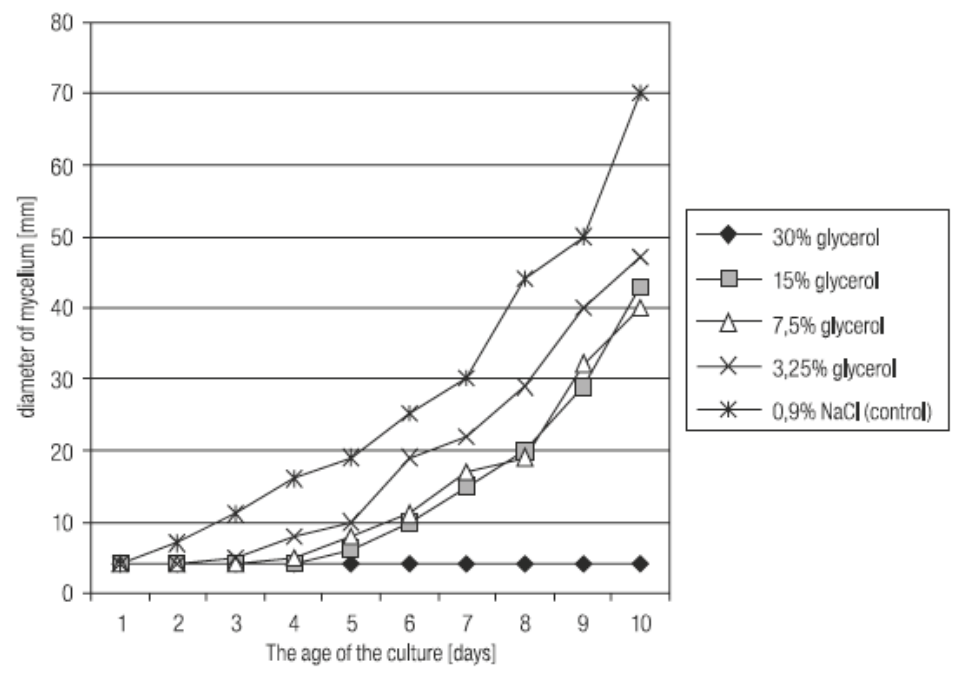

Fig. 2. Effect of glycerol on Pandora sp.growth.

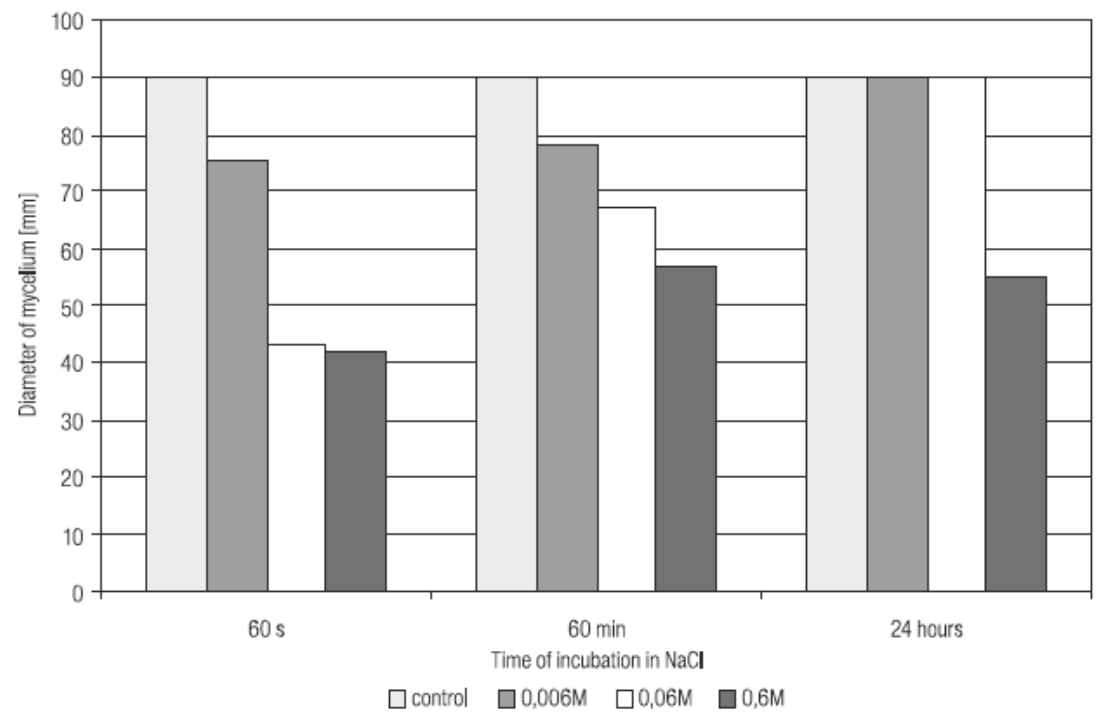

Fig. 3. Effect of $\mathrm{NaCl}$ concentration on Pandora sp. growth.

translocated on the solid full medium. After 48 hours, growth was noticed in the control ( $0 \%$ glycerol) and in the $3.5 \%$ glycerol solution. The rate of growth in particular variants of the medium has been visualised in Figure 2.

At concentration of $30 \%$, glycerol exerted a strongly inhibiting effect. In the other variants of glycerol concentration, mycelium growth was observed, but this was concomitant with the appearance of some structures that had not been noticed before. Samples of $15 \%$ and $7.5 \%$ concentrations were growing in the form of a coiled string, arising over the medium. The string created a thin clod which was difficult 
to fragment. The clod was surrounded by a delicate mycelium, which was easy to fragment. The adjacent zone, again, had the shape of a coiled string. The whole structure displayed a characteristic colony pattern.

When the mycelia were treated with glycerol, this was parallelled by a delayed production of spores which did not appear until the ninth day after the culture on the solid full medium had been started. The inhibition effect exerted by these glycerol concentrations implies that the fungus Pandora is exceptionally sensitive to water tranfer from the cells. So, there were performed tests with different concentrations of $\mathrm{NaCl}$, including those producing a hypertonic environment, which remove part of the water from the cells. The results of the tests are plotted in Figure 3.

In general, the rate of growth decreases with the increasing osmotic value of the medium in which the fungi were kept before being translocated onto the YPG medium. But surprisingly, as the time of incubation in $\mathrm{NaCl}$ increases, so does the vitality of the mycelium translocated from $\mathrm{NaCl}$ onto the solid full medium. After 24 hours of incubation in the hypotonic solutions $(0.006 \mathrm{M}$ and $0.06 \mathrm{M})$, the strain was growing as fast as in the control.

The results of irradiating the fungal mycelium with UV rays indicate that the UV rays did not affect the dynamics of growth in any of the strains. Only a change in the colour of the Paecilomyces and Hirsutella colony surface was noticed. With Paecilomyces irradiated for $60 \mathrm{~min}$., the typical pigment did not appear after 9 days of irradiation. Interestingly, on the days that followed the pigment alternately appeared and disappeared. Such phenomenon was not observed in any culture of the other investigated species.

\section{DISCUSSION}

Entomopathogenic fungi form a highly inhomogeneous group of eucaryotic organisms. The comparison of the three species (differing morphologically and unrelated in the sense of not belonging to the same rod) revealed strong differences in the rate of growth. Pandora grew much faster than the other species. But all of the strains grew fast enough to enable a comparative study of how the various factors affected the growth process. After 20-day observation of the increase in the diameter of Hirsutella, when the mycelium attained a diameter five times as large as the initial one, it was possible to examine the influence of the environment on microorganism growth, colony morphology, sporulation process and secondary metabolites production.

Our study also substantiated the importance of the method by which the samples of the cells were inoculated on/in the medium. Tearing off fragments of the mycelium and placing them on/in other media was very useful when starting a new culture. In some instances it is necessary to develop growth on the whole surface of a solid medium over a short period, and this is easy to achieve if we have a solution of spores. We started a new culture in order to prepare a solution of small fragmented mycelium and inoculate it afterwards. All the three fungi were found to grow fast after such inoculation. Pandora showed greater dynamics of sporulation under such conditions, probably owing to the mechanical stress triggered by the tearing-off of the micelium, which induced the sporulation process. 
The fungi under study responded differently to the method of placing them on the medium. Deep inoculation obtained by pouring the mycelium over a melted agar medium inhibited the growth of Pandora, while Hirsutella displayed no significant changes either in the morphology or the size of the colony. Morphological changes were detected in Paecilimyces. Compared to the control its colony was plain, without the characteristic pigment. These findings have led to the conclusion that the method of inoculation plays a particular role in the investigations of fungi.

An important requisite for laboratory experiments with microorganisms (also with fungi) is storing them at low temperature as museum strains. In many instances it is useful to keep them at $72^{\circ} \mathrm{C}$ in the glycerol medium. Our results, however, show that this procedure fails to be sufficient for Pandora. After 7-day storage in saline or in the glycerol medium for bacteria, the fungus survive at $6^{\circ} \mathrm{C}$; it did not survive when kept in the glycerol medium for yeast over the same period.

The question arises as to why Pandora shows greater sensitivity when kept in the glycerol medium for yeast storage. In this medium glycerol concentration is higher than in the YPG medium and Bacto Pepton has been replaced with Bacto Trypton. This indicates that the Pandora strain is very sensitive even to small changes in the composition of the medium. The Paecilomyces mycelium survived in each of the media used in our study, even after 7 weeks of incubation at minus $72^{\circ} \mathrm{C}$.

It is interesting to note that after incubation in saline at minus $18^{\circ} \mathrm{C}$ we observed the appearance of the spore producing structure referred to as coremia, but this process was affected by the composition of the medium. In the medium for bacteria and in the glycerol yeast medium coremia appeared after 7 days and after 24 hours of incubation, respectively; the structures in saline did not arise after 6 weeks.

These findings imply that even small changes in the composition of the medium and in the physical environment have to be considered when establishing the optimal conditions for the induction of sporulation in Paecilomyces. It suffices to keep the strain at $72^{\circ} \mathrm{C}$ in saline, not in the glycerol medium for yeast. As for Hirsutella, the strain survives when incubated in any of the medium variants used, but surprisingly not at plus $22^{\circ} \mathrm{C}$ in the glycerol medium for yeast over the incubation period of 7 weeks.

Our study of the low temperature effect suggests that glycerol might be the factor which negatively affects the viability of Pandora. More precise testing methods supported this suggestion. Even a $30 \%$ concentration of glycerol was able to kill the cells. Glycerol concentrations below $30 \%$ decreased the rate of colony growth and induced the appearance of unique morphological mycelium structures.

In order to describe the mechanism governing the impact of glycerol on Pandora we should take into account the fact that one molecule of glycerol absorbes three molecules of water, and this is what explains the removal of three water molecules from the cell interior. Anyway, it is difficult to accept that glycerol is transported in such amounts that enable a significant level of dehydration to be attained. Of greater importance seems to be the interaction of glycerol outside the cell. In terms of molar concentrations, these were the values of $0.35 \mathrm{M}, 0.8 \mathrm{M}$ and $1.6 \mathrm{M}$ at which the rate of Zoophthora growth slowed down. Sodium chloride as physiological liquid is considered to be iso-osmotic to yeast cells at the concentration of $0.15 \mathrm{M}$. This means that all the inhibiting solutions of glycerol were hypertonic, and therefore capable of removing water from the Pandora cells. The question is, does the fungus really have such a high sensitivity to water removal? 
The question has partly been answered in the course of our experiment involving various concentrations of sodium chloride. As expected, the more hypertonic was the habitat sorrunding the mycelium of Pandora, the slower became the growth rate. Although $\mathrm{NaCl}$ was found to act as a growth inhibiting factor, it did not kill the fungi cells.

UV radiation tests showed that exposure to UV rays did not affect the rate of growth of the mycelium. This was not surprising since the rays did not penetrate the cells in the lower parts of the colony, so they might have grown. While performing the experiments, it was interesting to observe the surface of the mycelium because the UV rays might have induced mutations changing its morphological traits. It is not unlikely that this factor could induce the production of telomorphic forms. Changes in the morphology of the surface were really noticed but they all pertained solely to the colour of the mycelium. Paecilomyces exposed to UV radiation for 60 min. developed the characteristic pigment only after 10 days of cultivation, but after another two days the pigment disappeared. Hirsutella lost the pigment in each time variant of UV radiation. The shape of the mycelium edge became less regular. The morphology of Pandora did not change as a result of exposure to UV radiation.

These findings are interesting in the context of relevant literature, where the inducing effect of ionising radiation on living cells is taken into account. According to some authors (Szot 1976), radiation energy is transferred to water molecules and afterwards translated to other compounds, producing the energization effect, which accounts for the increased activity of those compounds, including that of the enzymes.

\section{REFERENCES}

Bajan C., Kmit ow a K. 1997. Thirty years' studies on entomopathogenic fungi, Polish Ecological Studies, 23: 3-4, 133-154.

Brobin P. J., Wilding N., Clarc S. J. 1985. The persistence of infectivity of conidia of the aphid pathogen Erynia neoaphidis on leaves in the field, Ann. Appl. Biol. 107: 365-376.

Carruthers R. I., Hural K. 1990. Fungi as naturally occurring enthomopathogens. (In:) R.R. B aker, P.E. D u n n (eds). New Directions in Biological Control. Alan R. Liss, New York: 115-138.

Dromph K., Pell J. K., Eile nberg J. 1998. Sporulation of Erynia neoaphidis from Sitobion avenae cadavers, insect. Pathogens and Insect Parasitic Nematodes IOBC, Bulletin 21: 91-94.

Hall L. M., Bell J. V. 1961. Further studies on the effect of temperature on the growth of some entomophthorous fungi, Journal of Insect Pathology 3: 289-296.

Krejzovă R. 1988. The formation and discharge of conidia in cultures of entomophthorous fungi, Ćeska Mycologie 42: 31-41.

Ladge L. P. 1978. Growth and sporulation of Entomophthora virulenta on semidefined media in liquid culture, J. Invertebr. Pathol. 31: 225-233.

Miętkiewski R., Tkaczuk C., Zurek M., van der Geest L. P. S. 1994. Temperature requirements of four entomopathogenic fungi. Acta Mycol. 29 (1): 109-120.

Paterson R. R., Simmonds M. S., Blaney W. M. 1987. Mycopesticidal effects of characterised extracts of Penicillum isolates and purified secondary metabolites (including mycotoxins) on Drosophila melanogaster and Spodoptora littorali, Journal of Invertebrate Pathology 50: 124-133.

Różański L. 1992. Przemiany pestycydów w organizmach żywych i środowisku. PWRiL, Warszawa: 113-114.

Szot Z. 1976. Działanie promieniowania jonizującego na materię żywą. Postępy Techniki Jądrowej, Warszawa.

Uziel A., Ken ne th R. G. 1991. Survival of primary conidia and capilliconidia at different humidities in Erynia (subgen. Zoophthora) spp. and in Neozygites freseni (Zygomycotina, Entomophthorales) with special emphasis on Erynia radicans. J. Invertebr. Pathol. 58: 118-126. 
Wilding N. 1973. The survival of Entomophthora sp. In mummified apis at different temperatures and humidities, Journal of Invertebrate Pathology 21: 309-311.

Xavier I. J., Khachatourians G. B. 1996. The heat-shock response of 5 strains of entomopathogenic fungus Beauveria brongniarti, Canadian Journal of Microbiology 42: 577-585.

Yam a m ot o M., Aoki J. 1983. Periodicity of conidial discharge of Erynia radicans. Trans. Mycol. Soc. Japan 24: 487-496.

Yendol W. G. 1968. Factors affecting germination of Entomophthora conidia, Journal of Invertebrate Pathology 10: 116-121.

Wpływ czynników fizycznych na wzrost i zarodnikowanie grzybów owadobójczych

\section{Streszczenie}

Przetestowano wpływ wybranych czynników fizycznych oraz technik posiewu na wzrost i zarodnikowanie szczepów trzech gatunków grzybów owadobójczych: Hirsutella tompsonii, Paecilomyces sp. i Pandora sp. Zarówno technika posiewu, jak i czynniki takie jak temperatura, wartość osmotyczna środowiska, promieniowanie UV wpływają na wymienione cechy tych grzybów, chociaż wpływ ten jest różny w stosunku do poszczególnych szczepów. Niektóre uzyskane efekty, np. wytwarzanie przez Pandora sznurowatych struktur, czy letalny wpływ glicerolu w stosunku do Pandora, powiny być poddane bardziej szczegółowym badaniom w przyszłości. 